\section{Case Reports in Ophthalmology}

Case Rep Ophthalmol 2017;8:31-34

\title{
Accidental Ingestion of Nasal Packing Gauze during Endonasal Endoscopic Dacryocystorhinostomy under Local Anesthesia: A Case Report
}

\author{
Yoshiyuki Kitaguchi $^{\mathrm{a}} \quad$ Jacqueline Mupas-Uy ${ }^{\mathrm{a}} \quad$ Yasuhiro Takahashi $^{\mathrm{a}}$

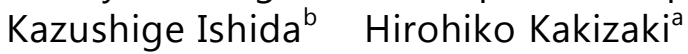 \\ ${ }^{a}$ Department of Oculoplastic, Orbital and Lacrimal Surgery, Aichi Medical University

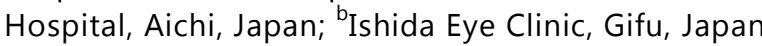

\section{Keywords}

Endonasal endoscopic dacryocystorhinostomy - Accidental ingestion · Nasal packing gauze . Local anesthesia

\begin{abstract}
Purpose: To report a case of accidental ingestion of a nasal packing gauze during endonasal endoscopic dacryocystorhinostomy (en-DCR) under local anesthesia. Case Report: A 66year-old female patient underwent an en-DCR for a right acquired nasolacrimal duct obstruction. The surgery was performed in a supine position under local anesthesia. An X-ray detectable ribbon gauze soaked in $0.02 \%$ epinephrine was placed in the middle meatus to prevent blood and liquid from flowing into the pharynx. The same packing gauze was also used for hemostasis during the surgery. At the end of the surgery, 1 piece of gauze was missing and could not be detected by the endonasal endoscopic exploration. An abdominal X-ray image performed on the same day demonstrated the presence of the gauze in the stomach although the patient did not notice swallowing the gauze. The gauze was not there on the Xray 1 week later. Conclusion: Surgeons need to be aware of accidental ingestion of a nasal packing gauze in en-DCR under local anesthesia. Keeping the gauze end out of the nostril is likely preventive for this complication. The use of X-ray detectable gauze was helpful to detect its location.


Kitaguchi et al.: Accidental Ingestion of Nasal Packing Gauze during Endonasal Endoscopic Dacryocystorhinostomy under Local Anesthesia: A Case Report

\section{Introduction}

Gauze for nasal packing is commonly used in endonasal endoscopic dacryocystorhinostomy (en-DCR) [1, 2]. This gauze with epinephrine provides vasoconstrictive effect for bleeding control [1]. However, complication is rarely mentioned in relation to this packing technique. A report illustrated that a nasal packing gauze fallen into the throat caused airway obstruction in an en-DCR just after a general anesthesia [2]. We here report a case of accidental ingestion of a nasal packing gauze during an en-DCR under local anesthesia.

\section{Case Report}

A 66-year-old woman underwent en-DCR for a right acquired nasolacrimal duct obstruction. The surgery was performed in a supine position under local anesthesia (1\% lidocaine and epinephrine diluted to 1:100,000) without sedation. X-ray detectable ribbon gauze soaked with $0.02 \%$ epinephrine was placed in the middle meatus to prevent blood and liquid from flowing into the pharynx (Fig. 1). The same packing gauze was also used for hemostasis during the surgery. The osteotomy was performed using an ultrasonic bone curette (Sonopet $^{\circledR}$; Stryker, Kalamazoo, MI, USA) [3]. The patient was instructed to spit out the irrigated fluid as needed.

At the end of the surgery, 1 piece of gauze was missing and could not be detected by the endonasal endoscopic exploration. Abdominal X-ray image on the same day demonstrated the presence of the gauze in the stomach although the patient did not notice swallowing the gauze (Fig. 2a, b). The gauze was not there on the X-ray 1 week later (Fig. 2c).

\section{Discussion}

We report a rare case of accidental ingestion of nasal packing gauze during an en-DCR under local anesthesia. A fallen nasal packing gauze into the throat or deeper potentially results in serious complication such as airway obstruction [2], aspiration [4], and bowel perforation [5]. Although the reported accidental ingestion of an en-DCR complication arose just after the extubate of a general anesthesia [2], this complication is proved as well to occur under local anesthesia.

The patient did not notice swallowing of the nasal packing gauze. The throat was anesthetized with overflowed anesthetic agent from the injection site because of the supine position [6], which was a possible reason.

The packing gauze swallowed by the patient was placed in the middle meatus, close to the throat. Whereas, the main surgical field of the en-DCR is just anterior to the middle concha $[1,3,6]$. The gauze was left, therefore, out of the view during the surgery. Keeping the gauze end out of the nostril is a good preventive measure. Alternative use of neuropatties with very long threads are likely helpful for managing surgical field as well.

The use of a gauze with X-ray detectable was helpful for detecting its missing [7]. If an ingested foreign object is found in the stomach after more than 4 weeks, it needs to be removed under an endoscopic guidance in general anesthesia [8]. In the present case, a plain $\mathrm{X}$-ray demonstrated that the gauze passed out of the body in 1 week. As well, the X-ray indicator also helped us to confirm that there was no retained gauze in the nasal and sinus cavities under a plain X-ray [7]. 
In conclusion, surgeons need to be aware of accidental ingestion of a nasal packing gauze in en-DCR under local anesthesia. Keeping the gauze end out of the nostril is likely preventive for this complication. The use of X-ray detectable gauze was helpful to detect its location.

\section{Statement of Ethics}

The Institutional Review Board of the Ethics Committee of Aichi Medical University Hospital approved this retrospective case report, which adhered to the tenets of the 1964 Declaration of Helsinki.

\section{Disclosure Statement}

The authors have no competing interests to declare.

\section{References}

1 Chong KK: Primary endoscopic dacryocystorhinostomy; in: Ali MJ (ed): Principles and Practice of Lacrimal Surgery. Berlin and Heidelberg, Springer, 2015, pp 195-201.

-2 Eipe N, Choudhrie A: Nasal pack causing upper airway obstruction. Anesth Analg 2005;100:1861.

-3 Kakizaki H, Kitaguchi Y, Takahashi Y, Mupas-Uy J, Mito H: Prevention of re-obstruction in watery eye treatment: three-flap technique in external dacryocystorhinostomy. Graefes Arch Clin Exp Ophthalmol 2016, DOI:10.1007/s00417-016-3490-z.

4 Walton SL: Postextubation foreign body aspiration: a case report. AANA J 1997;665:147-149.

-5 Hashmi SM, Gopaul SR, Sansom JR: Swallowed nasal pack: a rare but serious complication of the management of epistaxis. J Laryngol Otol 2004;118:372-373.

6 Chan W, Fahlbusch D, Dhillon P, Selva D: Assisted local anesthesia for powered endoscopic dacryocystorhinostomy. Orbit 2014;33:416-420.

7 Eisen GM, Baron TH, Dominitz JA, Faigel DO, Goldstein JL, Johanson JF, Mallery JS, Raddawi HM, Vargo JJ 2nd, Waring JP, Fanelli RD, Wheeler-Harbough J: Guideline for the management of ingested foreign bodies. Gastrointest Endosc 2002;55:802-806.

-8 Kim MG, Baek RM, Minn KW, Heo CY, Kwon SS, Park CY: Nasal packs with X-ray indicators. Ann Plast Surg 2006;56:342-343. 


\section{Case Reports in Ophthalmology}

(C) 2017 The Author(s). Published by S. Karger AG, Basel www.karger.com/cop

Kitaguchi et al.: Accidental Ingestion of Nasal Packing Gauze during Endonasal Endoscopic Dacryocystorhinostomy under Local Anesthesia: A Case Report

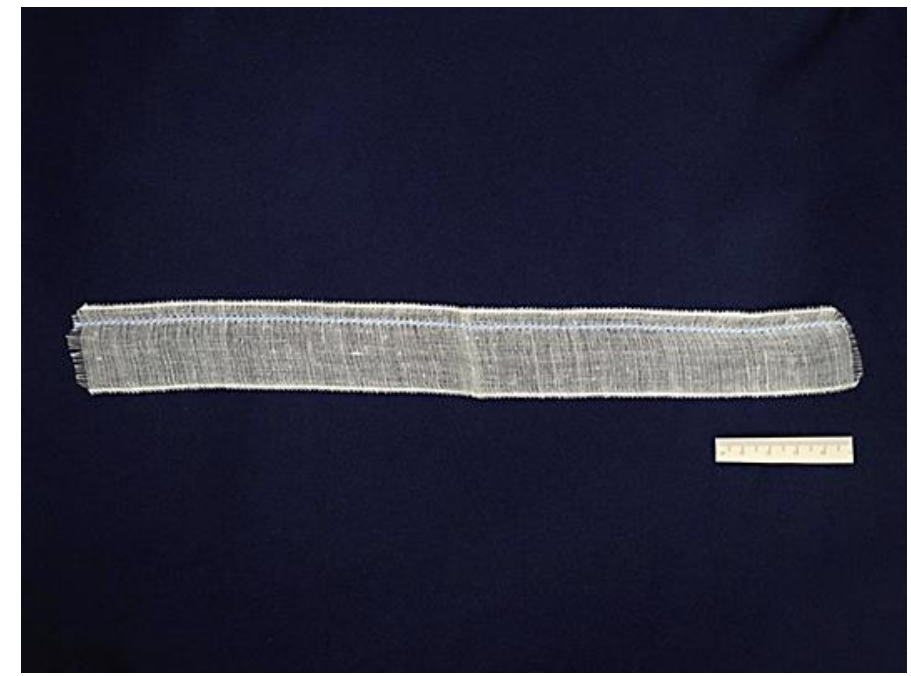

Fig. 1. An X-ray detectable nasal packing gauze with a size of $30 \times 3 \mathrm{~cm}$ used in the endonasal endoscopic dacryocystorhinostomy. The blue strip is X-ray detectable.
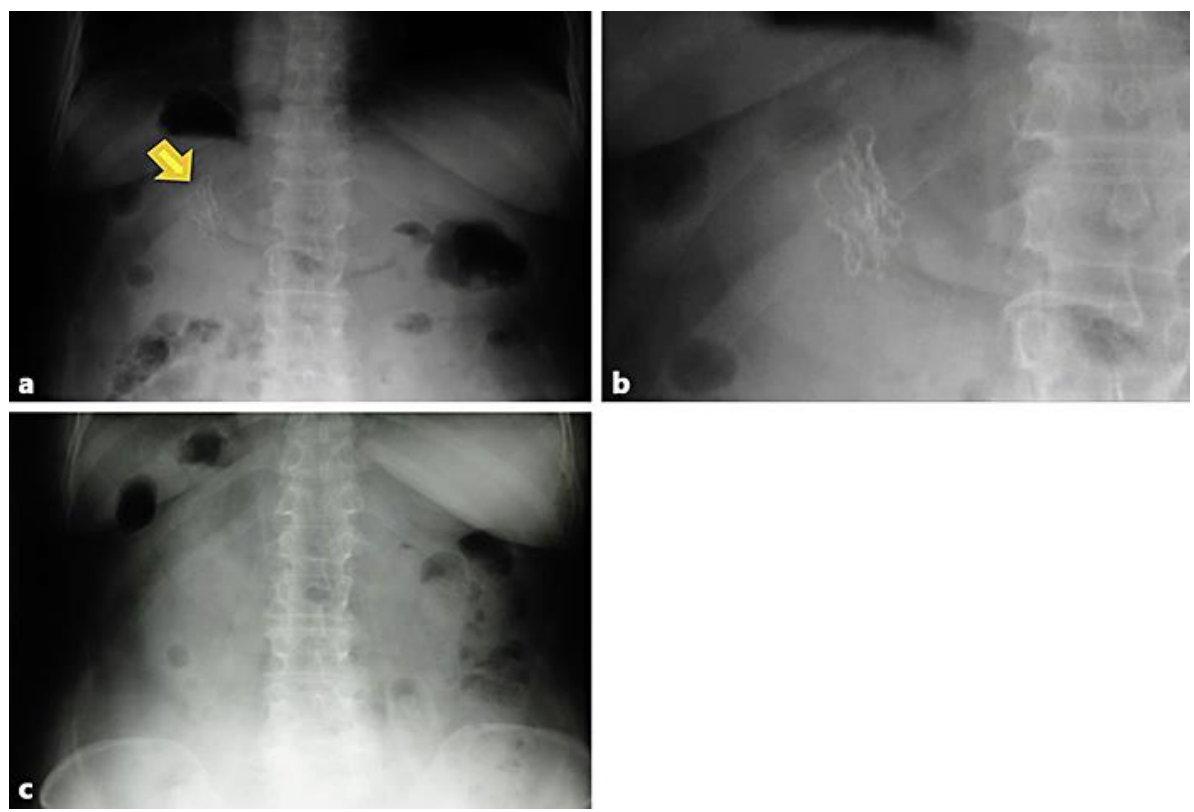

Fig. 2. Plain X-ray of the abdomen. a The nasal packing gauze with X-ray indicator is detected in the stomach on the same day of the surgery (arrow). b Magnified image. $\mathbf{c}$ The gauze disappeared 1 week later. 